Article

\title{
Antioxidative Categorization of Twenty Amino Acids Based on Experimental Evaluation
}

\author{
Naijin $\mathrm{Xu}$, Guanqun Chen and Hui Liu * \\ College of Medical Laboratory, Dalian Medical University, Dalian 116044, China; naijinxu@aliyun.com (N.X.); \\ guanqungq@163.com (G.C.) \\ * Correspondence: liuhui60@sina.com or immunology@dlmedu.edu.cn; Tel: +86-411-86110383
}

Received: 19 October 2017; Accepted: 23 November 2017; Published: 27 November 2017

\begin{abstract}
In view of the great importance bestowed on amino acids as antioxidants in oxidation resistance, we attempted two common redox titration methods in this report, including micro-potassium permanganate titration and iodometric titration, to measure the antioxidative capacity of 20 amino acids, which are the construction units of proteins in living organisms. Based on the relative intensities of the antioxidative capacity, we further conducted a quantitative comparison and found out that the product of experimental values obtained from the two methods was proven to be a better indicator for evaluating the relative antioxidative capacity of amino acids. The experimental results were largely in accordance with structural analysis made on amino acids. On the whole, the 20 amino acids concerned could be divided into two categories according to their antioxidative capacity. Seven amino acids, including tryptophan, methionine, histidine, lysine, cysteine, arginine and tyrosine, were greater in total antioxidative capacity compared with the other 13 amino acids.
\end{abstract}

Keywords: amino acid; total antioxidant capability; redox titration

\section{Introduction}

Oxidation resistance, as a normal, unavoidable and indispensable physiological process, plays a positive role in maintaining homeostasis in living organisms. However, when oxidation resistance surpasses the organism's immune burden, it will definitely bring detrimental consequence to the organism, even triggering various chronic, even life-threatening diseases. To counteract the over-oxidation imposed by different kinds of internal and external factors and adapt to the complicated and changeable environment, all the living organisms, especially higher animals like human beings, have gradually developed various fine-tuning anti-oxidizing systems in the long history of evolution. To date, we clearly know a variety of anti-oxidizing systems present in living organisms, and they include some enzymes, such as superoxide dismutase, catalase and glutathione peroxidase, etc. [1-3], various proteins, such as albumin, ceruloplasmin, ferritin, etc. [4-6], many compounds of relatively small molecules, such as ascorbic acid, $\alpha$-tocopherol, $\beta$-carotene, ubiquinol-10, glutathione (GSH), methionine, uric acid, bilirubin [7-9] and hydroxytyrosol, etc. [10,11], and some hormones, such as estrogen, angiotensin and melatonin, etc. [12-14].

Admittedly, the vital important role of antioxidants in healthcare and disease prevention lead many researchers to the investigation of the antioxidative capacity of various bioactive substances, such as plants [15], animal proteins [16] and several amino acids [17]. Amino acids, to be accurate, alpha-amino acids, the building blocks of proteins in living organisms, naturally attract researchers' attention. Mostly, the amino acids in vivo exist in proteins, but they are also present in our body fluids as free forms [18]. Therefore, studying the antioxidative activity of amino acids will deepen the understanding of what role these life-sustaining substances play in oxidation resistance. 
Although structural analysis may probably arrive at a rough estimation on the antioxidative capacity of amino acids, it is necessary to carry out quantitative studies on all those amino acids found in the body to accurately sort these amino acids in terms of antioxidative capacity. In the present study, we have employed two methods to make a preliminary quantitative analysis of the antioxidative activity of 20 amino acids. Based on this study, it is possible to deduce the antioxidative capacity of certain peptides and proteins.

\section{Materials and Methods}

\subsection{Reagents and Instruments}

Potassium permanganate, sodium oxalate, iodine, potassium iodide, potassium dichromate and sodium thiosulfate were of analytical grade, and the 20 -amino acid kit was obtained from Accustandard (New Haven, CT, USA). Using the molecular weight data for the amino acids, as supplied (Table 1), solutions were prepared with distilled water to give amino acid concentrations of $0.5 \mathrm{~mol} / \mathrm{L}$.

Table 1. Molecular weights of amino acids.

\begin{tabular}{cccccc}
\hline Amino Acid & Molecular Weight & Amino Acid & Molecular Weight & Amino Acid & Molecular Weight \\
\hline Alanine & 89.09 & Glycine & 75.07 & Proline & 115.13 \\
Arginine & 174.20 & Histidine & 155.15 & Serine & 105.09 \\
Asparagine & 132.12 & Phenylalanine & 165.19 & Threonine & 119.12 \\
Aspartic acid & 133.10 & Isoleucine & 131.17 & Tryptophan & 204.23 \\
Cysteine & 121.16 & Leucine & 131.17 & Tyrosine & 181.19 \\
Valine & 117.15 & Lysine & 146.19 & Glutamine & 146.14 \\
Glutamic acid & 147.13 & Methionine & 149.21 & - & - \\
\hline
\end{tabular}

\subsection{Micro-Potassium Permanganate Method}

The micro-potassium permanganate method was used to measure total antioxidant capacity (AOC) according to the literature [19]. The potassium permanganate solution was prepared by firstly dissolving $0.316 \mathrm{~g}$ of potassium permanganate in $50 \mathrm{~mL}$ of distilled water, and then, the mixture was further diluted to $100 \mathrm{~mL}$ in a volumetric flask. The solution prepared was stored in a brown reagent bottle. The potassium permanganate solution was standardized with standard sodium oxalate solution. The actual concentration of $\mathrm{KMnO}_{4}$ solution was $0.019 \mathrm{~mol} / \mathrm{L}$; this was diluted to $0.005 \mathrm{~mol} / \mathrm{L}$ to give the working solution.

Each amino acid solution of $0.5 \mathrm{~mol} / \mathrm{L}$ was diluted in a ratio of 1:10 with distilled water to give $0.05 \mathrm{~mol} / \mathrm{L}$. This was repeated to give a series of solutions with five concentrations: $5 \times 10^{-2}$, $2.5 \times 10^{-2}, 1.25 \times 10^{-2}, 6.2 \times 10^{-3}$ and $3.125 \times 10^{-3} \mathrm{~mol} / \mathrm{L}$.

Twenty microliters of each dilution were transferred to a 96-well microtiter plate; $80 \mu \mathrm{L}$ of a $0.005 \mathrm{~mol} / \mathrm{L} \mathrm{KMnO}_{4}$ solution were then added to each well in the plate. The plate was put in an oscillator for $15 \mathrm{~s}$ to make sure that each mixture was homogeneous. The plate was then put in a water bath at $37^{\circ} \mathrm{C}$ for $30 \mathrm{~min}$. Then, OD measurements were performed using a microplate spectrophotometer. The wavelength selected was $550 \mathrm{~nm}$.

Each sample, with five different concentrations, gave five OD values as shown Figure 1. With five OD values available, it was better to select the area under curve (AUC) to give an assessment of the total AOC as follows:

A graph including the logarithm of the concentration of an amino acid $(-1.30,-1.60,-1.90$, -2.20 and -2.50 ) on the $X$-axis versus $O D$ values on the Y-axis was plotted (Figure 1). The regression curve obtained by the Statistics software (SPSS) 15.0 package (SPSS Inc., Chicago, IL, USA, 2006) is presented in Figure 1. 


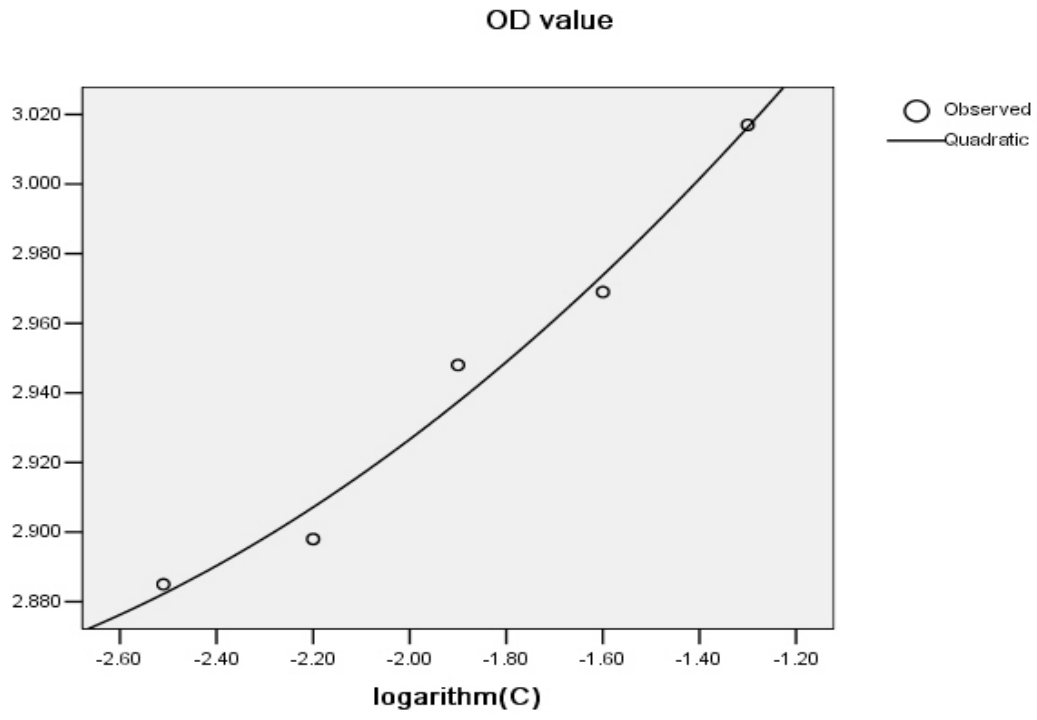

Figure 1. Regression curve of one sample. Where $X$ represents the logarithm of sample dilution times, while $\mathrm{Y}$ represents the OD value.

The quadratic regression equation obtained was $\mathrm{Y}=0.032 \mathrm{X}^{2}+0.234 \mathrm{X}+3.266$, where $\mathrm{a}=0.032$, $\mathrm{b}=0.234, \mathrm{c}=3.266$.

The integral formula below was applied to calculate the AUC, which represented the antioxidative capacity of substances reacting with permanganate.

$$
\int_{\mathrm{k}_{1}}^{\mathrm{k}_{2}} \mathrm{ax}^{2}+\mathrm{bx}+\mathrm{cdx}=\frac{\mathrm{a}}{3} \mathrm{x}^{3}+\frac{\mathrm{b}}{2} \mathrm{x}^{2}+\mathrm{cx}=(1 / 3) \times \mathrm{a}\left(\mathrm{k}_{2}^{3}-\mathrm{k}_{1}^{3}\right)+(1 / 2) \times \mathrm{b} t\left(\mathrm{k}_{2}^{2}-\mathrm{k}_{1}^{2}\right)+\mathrm{c}\left(\mathrm{k}_{2}-\mathrm{k}_{1}\right)
$$

where $k_{1}$ and $k_{2}$ were -2.51 and -1.30 , representing the logarithm of the lowest and highest dilutions, respectively. The substitution of the values of $a, b$ and $c$ into the equation resulted in a value of 3.558, which represented the area under the curve. If $R^{2}<0.95$, the area was calculated by the ladder-shaped method [19]. The AUC was in inverse proportion to AOC.

\subsection{Micro-Iodometric Method}

The micro-iodometric method was also used to measure total AOC according to the literature [19]. Following the same procedure for preparing potassium permanganate solution, $100 \mathrm{~mL}$ of iodine solution $(0.05 \mathrm{~mol} / \mathrm{L})$ were prepared and then diluted to a concentration of $0.0015 \mathrm{~mol} / \mathrm{L}$. The prepared solution was stored in a brown reagent bottle. Indirect titration was employed for the standardization of the iodine solution, using standard potassium dichromate and sodium thiosulfate.

In the same way, $100 \mathrm{~mL}$ of starch solution $(0.005 \mathrm{~g} / \mathrm{mL})$ were prepared.

For the inverse titration method, $0.0015 \mathrm{~mol} / \mathrm{L}$ iodine solution were diluted to five different concentrations by arithmetic dilution. Initially, 100, 80, 60, 40 and $20 \mu \mathrm{L}$ of iodine solution were added to five test tubes followed by $0,20,40,60$ and $80 \mu \mathrm{L}$ of distilled water, respectively, to give iodine solutions of $1.5 \times 10^{-3}, 1.2 \times 10^{-3}, 0.9 \times 10^{-3}, 0.6 \times 10^{-3}$ and $0.3 \times 10^{-3} \mathrm{~mol} / \mathrm{L}$.

To each of the five test tubes, an equal amount of starch solution was added, so the original concentrations of iodine solution were halved. Eighty microliters of each mixed solution were added to the wells of a 96-well microtiter plate.

Each amino acid solution of concentration $0.5 \mathrm{~mol} / \mathrm{L}$ was diluted to $0.05 \mathrm{~mol} / \mathrm{L}$. Twenty microliters of the sample to be measured were added to each well in the microtiter plate. The plate was then oscillated for $15 \mathrm{~s}$, to ensure that each mixture was homogeneous. The plate was then placed in a water bath at $37^{\circ} \mathrm{C}$ for $30 \mathrm{~min}$. 
OD measurements were performed using a Microplate Spectrophotometer. The wavelength selected was $570 \mathrm{~nm}$. As described for the micro-potassium permanganate method, the AUC was also in inverse proportion to the AOC.

\subsection{Quantitative Analysis}

The test with each sample was repeatedly performed three times, and then, the median value obtained from the three tests was taken as the observed value. The product of the experimental data obtained by the two methods was considered as a quantitative index to analyze the antioxidative ability. A lower value sample was considered as a stronger antioxidative activity. Experimental data were ranked by quantitative index. A graph including the rank number on the $X$-axis versus quantitative index on the Y-axis was plotted to sort twenty amino acids based on quantitative index of AOC.

\subsection{Statistical Analysis}

The relationship between the results from the two methods was assessed by the correlation test. The analysis was conducted using SPSS statistical analysis software. $p$-Values less than 0.05 (two-tailed) were considered to be statistically significant.

\section{Results}

The results in Table 2 show that the detection results from the two method were highly correlated $(\mathrm{r}=0.869, p<0.001)$. Different amino acids had different antioxidative activities; seven amino acids, including tryptophan, methionine, histidine, lysine, cysteine, arginine and tyrosine, had strong antioxidative activity, where the others had lower or almost no antioxidant activity, as shown in Figure 2.

Table 2. Comparison of the antioxidant activity of amino acids based on experimental results.

\begin{tabular}{|c|c|c|c|c|c|c|c|}
\hline \multirow{2}{*}{ Amino Acid } & \multicolumn{3}{|c|}{ Antioxidant Activity } & \multirow{2}{*}{ Amino Acid } & \multicolumn{3}{|c|}{ Antioxidant Activity } \\
\hline & AUC-Mn & AUC-I & Total & & AUC-Mn & AUC-I & Total \\
\hline Tryptophan & 0.953 & 0.057 & 0.054 & Valine & 3.551 & 2.121 & 7.532 \\
\hline Methionine & 1.151 & 0.049 & 0.056 & Serine & 3.397 & 2.232 & 7.582 \\
\hline Histidine & 1.198 & 0.056 & 0.067 & Glycine & 3.572 & 2.177 & 7.776 \\
\hline Lysine & 1.931 & 0.158 & 0.305 & Glutamine & 3.556 & 2.198 & 7.816 \\
\hline Cysteine & 1.851 & 0.198 & 0.366 & Threonine & 3.507 & 2.297 & 8.056 \\
\hline Arginine & 2.969 & 0.289 & 0.858 & Asparagine & 3.598 & 2.257 & 8.121 \\
\hline Tyrosine & 1.146 & 1.324 & 1.517 & Isoleucine & 3.596 & 2.334 & 8.393 \\
\hline Proline & 3.202 & 2.188 & 7.006 & Glutamic & 3.584 & 2.498 & 8.953 \\
\hline Alanine & 3.558 & 1.972 & 7.016 & Aspartic & 3.773 & 2.475 & 9.338 \\
\hline Phenylalanine & 3.471 & 2.107 & 7.313 & $\mathrm{r}(p)$ & \multicolumn{2}{|c|}{$0.869(<0.001)$} & \\
\hline Leucine & 3.530 & 2.125 & 7.501 & Blank control & 3.610 & 2.381 & 8.595 \\
\hline
\end{tabular}

AUC-Mn: the area under the curve for the potassium permanganate method; AUC-I: the area under the curve for the iodometric method; Total: total antioxidant activity (product of the experimental data obtained from the two methods). 


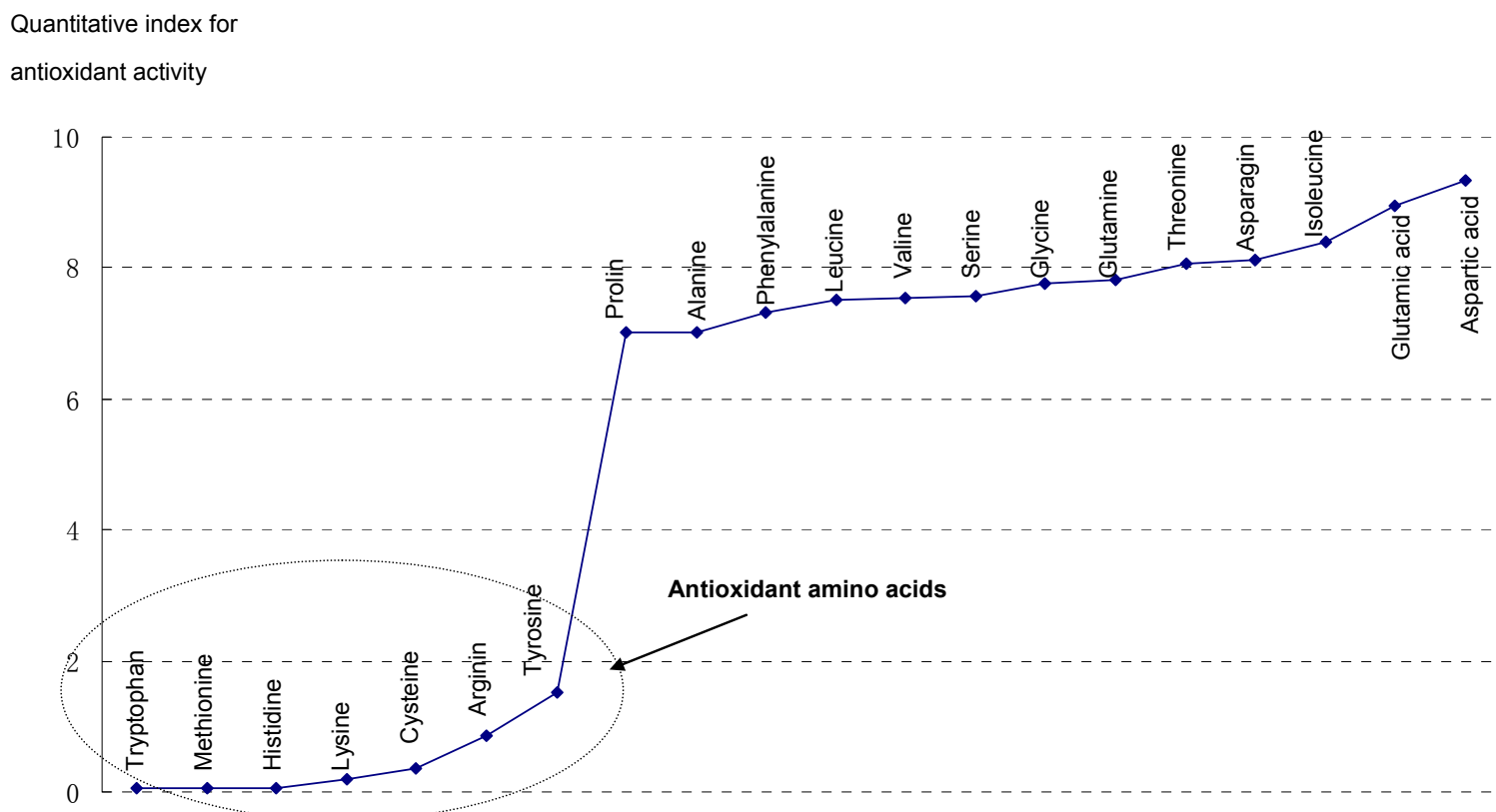

Figure 2. Categorization of twenty amino acids based on experimental evaluation. The value of quantitative index is inversely proportional to antioxidant activity.

\section{Discussion}

As stated in the Introduction, a greatly integrated antioxidative system exists in the body [20]. Under normal circumstances, the free radicals in the body are always in dynamic equilibrium with the antioxidative system [21]. Since serum albumin plays an important role in antioxidation [22,23], to simulate the real scenario in vivo, the concentrations of the amino acids in the experiments were set to be the total level of human plasma protein (the concentration of human serum protein is $70 \mathrm{~g} / \mathrm{L}$ ). The mean concentration of the 20 amino acids used in our research was appropriately $0.5 \mathrm{~mol} / \mathrm{L}$, and this could provide a sensible comparison.

The oxidation processes of amino acids involve very complex kinetics and mechanisms. The following is a brief elucidation for some amino acids.

The group of amino acids we studied is the so-called $\alpha$-amino acids. They all contain an amino group $\left(\mathrm{NH}_{2}\right)$, a carboxyl group $(\mathrm{COOH})$, a hydrogen $(\mathrm{H})$ and a side chain $(\mathrm{R})$, with $\mathrm{NH}_{2}$ attached to the $\alpha$-carbon, which is next to the $\mathrm{COOH}$. At physiological $\mathrm{pH}$ values, these amino acids exist mainly as dipolar ions (or zwitterions) [24]. Due to structural differences in the side chains, the antioxidation mechanisms and capacity of these amino acids vary greatly.

There are seven amino acids with strong antioxidative capacity, whose structures are shown in Figure 3.

Amino acids with electron-rich aromatic rings in side chains, e.g., tryptophan and tyrosine, are easily oxidized. Because the tryptophan molecule contains a pyrrole ring, with five ring atoms (four carbon atoms and one nitrogen atom) sharing six electrons, it is susceptible to oxidants. In particular, tyrosine has a benzene ring highly activated by a very strong electron-donating hydroxyl $(\mathrm{OH})$, and therefore, it is vulnerable to attack by an oxidant.

Amino acids with sulfur atoms in side chains, such as cysteine and methionine, are also easily oxidized. This is because the sulfur atom not only has two lone electron pairs, but also is relatively large, which makes it easy to oxidize.

To some degree, amino acids with nitrogen atoms in their side chains, such as histidine, lysine and arginine, are readily oxidized. This is because the nitrogen atom has one lone electron pair, so these amino acids can also be attacked by oxidants. 
<smiles>[NH3+]C(Cc1cn([TlH2])c2ccccc12)C(=O)[O-]</smiles>
tryptophan

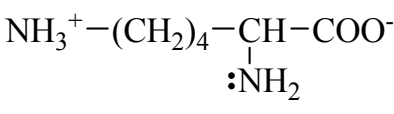

lysine<smiles>NC(=[NH2+])NCCCCC(N)C(=O)[O-]</smiles>

arginine<smiles>CSCCC([NH3+])C(=O)[O-]</smiles>

Figure 3. Amino acids with strong antioxidant ability.

Amino acids with stable groups and atoms (such as alkyl group, phenyl group) in their side chains are inert to oxidizing agents, exhibiting lower or no antioxidative capability. Included in this category are glycine, alanine, valine, leucine, isoleucine, threonine, serine, aspartate, glutamate, asparagine, glutamine, phenylalanine and proline.

Although antioxidant activity could be predicted based on amino acid structures, further testing may help to elucidate more accurate trends, as well as nonlinear relationships [25]. The two methods used in this paper are widely accepted for the determination of antioxidative activity; the principles involved are different. The micro-potassium permanganate method depends on the fact that potassium permanganate is a strong oxidant [26] and that it can react with reducing agents to generate brown hydrated manganese dioxide in weak acidic, neutral or alkaline solutions. The iodometric method is based on the principle that the standard electrode potential of the $\mathrm{I}_{2} / \mathrm{I}^{-}$pair is neither high nor low, so iodine can act as either an oxidizing or reducing agent, depending on the conditions [27,28]. We wish to determine if the two methods confirm each other, in order to obtain reliable results. The antioxidative ability of amino acids and their relative intensities cannot be assessed with accuracy, so it is necessary to perform systematic experiments and make a quantitative comparison. The results from the two methods indicate that they are highly consistent for most amino acids, but for a few, the methods display some inconsistency from the different ways according to different principles. We have therefore chosen the product of experimental values obtained from the two methods as an evaluating index of AOC for amino acids. The experimental results are largely in accordance with theoretical analysis of the antioxidative ability of these amino acids.

The limitation of this study is that AOCs should be compared between amino acids and other antioxidants. However, our initial thinking was just to classify the 20 alpha-amino acids based on the total antioxidant capacity, and we compared in different ways and determined to choose a relative one to arrive at our purpose. We will do further research on this topic in the near future.

\section{Conclusions}

Twenty amino acids could roughly be classified into two categories according to their antioxidative capacity. Seven amino acids, including tryptophan, methionine, histidine, lysine, cysteine, arginine and tyrosine, called antioxidative amino acids, were greater in total antioxidative capacity than the other 13 amino acids.

Author Contributions: H.L. conceived and designed the experiments; N.X. analyzed the data and wrote the paper; G.C. performed the experiments and analyzed the data.

Conflicts of Interest: The authors declare that they have no conflict of interest. 


\section{References}

1. Luangwattananun, P.; Eiamphungporn, W.; Songtawee, N.; Bülow, L.; Isarankura, N.; Ayudhya, C.I.N.; Prachayasittikul, V.; Yainoy, S. Improving enzymatic activities and thermostability of a tri-functional enzyme with SOD, catalase and cell-permeable activities. J. Biotechnol. 2017, 247, 50-59. [CrossRef] [PubMed]

2. Hanna, C.; Michał, S.; Monika, M.; Małgorzata, P.; Rusłan, S.; Grytner-Zięcina, B. Enzymatic antioxidant system in the cestode Hymenolepis diminuta after chronic infection of the rat. Cent. Eur. J. Biol. 2012, 7, 987-995.

3. Pieme, C.A.; Tatangmo, J.A.; Simo, G.; Nya, P.C.B.; Moor, V.J.A.; Moukette, B.M.; Nzufo, F.T.; Nono, B.L.N.; Sobngwi, E. Relationship between hyperglycemia, antioxidant capacity and some enzymatic and non-enzymatic antioxidants in African patients with type 2 diabetes. BMC Res. Notes 2017, 10, 141. [CrossRef] [PubMed]

4. Serbanescu, G.L.; Gruia, M.I.; Bara, M.; Anghel, R.M. The evaluation of the oxidative stress for patients receiving neoadjuvant chemoradiotherapy for locally advanced rectal cancer. J. Med. Life 2017, 10, 99-103. [PubMed]

5. Pietro, V.; Mercedes, A.P.; Carme, R. Catalases versus peroxidases: DFT investigation of $\mathrm{H}_{2} \mathrm{O}_{2}$ oxidation in models systems and implications for heme protein engineering. J. Inorg. Biochem. 2012, 117, 292-297.

6. Italia, K.; Chandrakala, S.; Ghosh, K.; Colah, R. Can hydroxyurea serve as a free radical scavenger and reduce iron overload in $\beta$-thalassemia patients? Free Radic. Res. 2016, 50, 959-965. [CrossRef] [PubMed]

7. Rahaiee, S.; Hashemi, M.; Shojaosadati, S.A.; Moini, S.; Razavi, S.H. Nanoparticles based on crocin loaded chitosan-alginate biopolymers: Antioxidant activities, bioavailability and anticancer properties. Int. J. Biol. Macromol. 2017, 9, 401-408. [CrossRef] [PubMed]

8. Gholivand, S.; Lasekan, O.; Tan, C.P.; Abas, F.; Wei, L.S. Comparative study of the antioxidant activities of some lipase-catalyzed alkyl dihydrocaffeates synthesized in ionic liquid. Food Chem. 2017, 224, 365-371. [CrossRef] [PubMed]

9. Barim-Oz, O.; Sahin, H. The influence of dietary antioxidant on ovarian eggs and levels of vitamin E, C, A, astaxanthin, $\beta$-carotene and oxidative stres in tissues of Astacus leptodactylus (Eschscholtz) during reproduction. Cell. Mol. Biol. (Noisy le Grand) 2016, 62, 1-10. [CrossRef] [PubMed]

10. Bernini, R.; Merendino, N.; Romani, A.; Velotti, F. Naturally occurring hydroxytyrosol: Synthesis and anticancer potential. Curr. Med. Chem. 2013, 20, 655-670. [CrossRef] [PubMed]

11. Bernini, R.; Montani, M.S.G.; Merendino, N.; Romani, A.; Velotti, F. Hydroxytyrosol-Derived Compounds: A Basis for the Creation of New Pharmacological Agents for Cancer Prevention and Therapy. J. Med. Chem. 2015, 58, 9089-9107. [CrossRef] [PubMed]

12. Kandemir, Y.B.; Aydin, C.; Gorgisen, G. The effects of melatonin on oxidative stress and prevention of primordial follicle loss via activation of mTOR pathway in the rat ovary. Cell. Mol. Biol. (Noisy le Grand) 2017, 63, 100-106. [CrossRef] [PubMed]

13. Diamanti-Kandarakis, E.; Dattilo, M.; Macut, D.; Duntas, L.; Gonos, E.S.; Goulis, D.G.; Gantenbein, C.K.; Kapetanou, M.; Koukkou, E.; Lambrinoudaki, I.; et al. Combo endo team: 2016. Mechanisms in endocrinology: Aging and anti-aging: A Combo-Endocrinology overview. Eur. J. Endocrinol. 2017, 176, R283-R308. [CrossRef] [PubMed]

14. Li, M.; Liu, X.; He, Y.; Zheng, Q.; Wang, M.; Wu, Y.; Zhang, Y.; Wang, C. Celastrol attenuates angiotensin II mediated human umbilical vein endothelial cells damage through activation of Nrf2/ERK1/2/Nox2 signal pathway. Eur. J. Pharmacol. 2017, 797, 124-133. [CrossRef] [PubMed]

15. Matsuura, H.N.; Poth, A.G.; Yendo, A.C.; Fett-Neto, A.G.; Craik, D.J. Isolation and Characterization of Cyclotides from Brazilian Psychotria: Significance in Plant Defense and Co-occurrence with Antioxidant Alkaloids. J. Nat. Prod. 2016, 79, 3006-3013. [CrossRef] [PubMed]

16. Chalamaiah, M.; Kumar, B.D.; Hemalathab, R.; Jyothirmayi, T. Fish protein hydrolysates: Proximate composition, amino acid composition, antioxidant activities and applications: A review. Food Chem. 2012, 135, 3020-3038. [CrossRef] [PubMed]

17. Hwang, H.S.; Winkler-Moser, J.K. Antioxidant activity of amino acids in soybean oil at frying temperature: Structural effects and synergism with tocopherols. Food Chem. 2017, 221, 1168-1177. [CrossRef] [PubMed]

18. Huichun, W.; Huaming, C.; Chyuanyuan, S. Free amino acids and peptides as related to antioxidant properties in protein hydrolysates of mackerel (Scomber austriasicus). Food Res. Int. 2003, 36, 949-957. 
19. Zhang, M.; Liu, N.; Liu, H. Determination of the Total Mass of Antioxidant Substances and Antioxidant Capacity per Unit Mass in Serum Using Redox Titration. Bioinorg. Chem. Appl. 2014, 2014, 928595. [CrossRef] [PubMed]

20. Zhou, Y.; Chen, J.; Wang, Z.; Liu, H. Evaluating the Risk of Tumors Diseases Based on Measurement of Urinary and Serumal Antioxidants Using the New Agar Diffusion Methods. Oxid. Med. Cell. Longev. 2017, 2017, 6578453. [CrossRef] [PubMed]

21. Marian, V.; Dieter, L.; Jan, M.; Mark, T.D.C.; Milan, M.; Joshua, T. Free radicals and antioxidants in normal physiological functions and human disease. Int. J. Biochem. Cell Biol. 2007, 39, 44-84.

22. Cao, T.; Xu, N.; Wang, Z.; Liu, H. Effects of Glutathione S-Transferase Gene Polymorphisms and Antioxidant Capacity per Unit Albumin on the Pathogenesis of Chronic Obstructive Pulmonary Disease. Oxid. Med. Cell. Longev. 2017, 2017, 6232397. [CrossRef] [PubMed]

23. Kanti, B.P.; Mohd, M.M.; Pawan, K.M.; Syed, I.R. Plasma protein oxidation and its correlation with antioxidant potential during human aging. Dis. Mark. 2010, 29, 31-36.

24. Stryer, L. Biochemistry, 4th ed.; W H Freeman and Company: New York, NY, USA, 1995; pp. $19-23$.

25. Garrett, A.R.; Weagel, E.G.; Martinez, A.D.; Heaton, M.; Robison, R.A.; O'Neill, K.L. A novel method for predicting antioxidant activity based on amino acid structure. Food Chem. 2014, 158, 490-496. [CrossRef] [PubMed]

26. Zhou, Y.; Zhang, M.; Liu, H. Total Antioxidant Capacity of Serum Determined Using the Potassium Permanganate Agar Method Based on Serum Diffusion in Agar. Bioinorg. Chem. Appl. 2015, 2015, 406071. [CrossRef] [PubMed]

27. Zhou, Y.; Xu, N.; Zhang, M.; Liu, H. A New Method for Measuring Total Antioxidant Capacity in Urine using the Iodine Starch agar Based on agar Diffusion. Curr. Anal. Chem. 2016, 11, 1-6. [CrossRef]

28. Cao, T.; He, M.; Bai, T.; Liu, H. Establishment of a Method for Measuring Antioxidant Capacity in Urine, Based on Oxidation Reduction Potential and Redox Couple I2/KI. Bioinorg. Chem. Appl. 2016, 2016, 7054049. [CrossRef] [PubMed]

Sample Availability: Not available.

(C) 2017 by the authors. Licensee MDPI, Basel, Switzerland. This article is an open access article distributed under the terms and conditions of the Creative Commons Attribution (CC BY) license (http://creativecommons.org/licenses/by/4.0/). 